\title{
The Role of Selected Chemokines in the Peritoneal Fluid of Women with Endometriosis-Participation in the Pathogenesis of the Disease
}

\author{
Marta Smycz-Kubańska *, Zdzisława Kondera-Anasz, Justyna Sikora, Dominika Wendlocha, \\ Patrycja Królewska-Daszczyńska, Aleksandra Englisz, Aleksandra Janusz, Joanna Janusz \\ and Aleksandra Mielczarek-Palacz (i)
}

check for updates

Citation: Smycz-Kubańska, M.; Kondera-Anasz, Z.; Sikora, J.; Wendlocha, D.; Królewska-Daszczyńska, P.; Englisz, A.; Janusz, A.; Janusz, J.; Mielczarek-Palacz, A. The Role of Selected Chemokines in the Peritoneal Fluid of Women with Endometriosis-Participation in the Pathogenesis of the Disease. Processes 2021, 9, 2229. https://doi.org/ $10.3390 /$ pr9122229

Academic Editor: Alina Pyka-Pajak

Received: 8 November 2021

Accepted: 6 December 2021

Published: 10 December 2021

Publisher's Note: MDPI stays neutral with regard to jurisdictional claims in published maps and institutional affiliations.

Copyright: (c) 2021 by the authors. Licensee MDPI, Basel, Switzerland. This article is an open access article distributed under the terms and conditions of the Creative Commons Attribution (CC BY) license (https:// creativecommons.org/licenses/by/ $4.0 /)$.
Department of Immunology and Serology, Faculty of Pharmaceutical Sciences in Sosnowiec, Medical University of Silesia, 40-055 Katowice, Poland; zanasz@sum.edu.pl (Z.K.-A.); sikoraj@poczta.onet.pl (J.S.); dwendlocha@sum.edu.pl (D.W.); pdaszczynska@sum.edu.pl (P.K.-D.); aenglisz@sum.edu.pl (A.E.); ajanusz@sum.edu.pl (A.J.); asia25@onet.pl (J.J.); apalacz@sum.edu.pl (A.M.-P.)

* Correspondence: mkubanska@sum.edu.pl

\begin{abstract}
Endometriosis is a disorder characterized by the presence of endometrial tissue outside the uterine cavity, primarily into the peritoneal cavity. It is known as a complex, chronic inflammatory disease and it is strongly associated with immune dysregulation. Various soluble mediators of the immune and inflammatory responses, including chemokines, play an important role in these processes. The aim of the study was to understand the role of the chemokines MCP-1, MCP-2, MCP-3, MCP-4, MIP-1 $\alpha$, MIP-1 $\beta$, eotaxin 2, eotaxin 3, ENA-78, and fractalkine in the development of endometriosis through their assessment in the peritoneal fluid of women with endometriosis. The study group included 58 women with endometriosis who were diagnosed during laparoscopy and then confirmed by histopathology. In 15 women from the reference group, laparoscopic examination demonstrated a normal status of the pelvic organs without any evidence of endometriosis nor inflammation in the peritoneal cavity. The peritoneal fluid of women with endometriosis and of women from the reference group were examined. To determine the concentration of the studied chemokines, enzyme immunoassays for Lumine ${ }^{\circledR}$ platforms were used. In the peritoneal fluid of women with endometriosis, a statistically significant increase in the concentration of MIP- $1 \beta$, eotaxin 2, eotaxin 3, ENA-78, and fractalkine and a decrease in the concentration of MCP-1, MCP-2, MCP-3, MCP-4, and MIP-1 $\alpha$ were observed compared to the reference group. The concentration of these cytokines depended on the severity of the disease. Changes in the concentration of the studied chemokines in the peritoneal fluid of women with endometriosis suggest their participation in the pathogenesis of the disease. The differences in chemokines concentration observed in different stages of endometriosis may be associated with the presence of inflammation in the peritoneal cavity at each step of disease development.
\end{abstract}

Keywords: endometriosis; chemokines; peritoneal fluid; inflammation

\section{Introduction}

Endometriosis is a non-malignant gynecological disorder that affects at least $10 \%$ of women. It is characterized by the implantation and growth of endometrial-like tissue, including glands and stroma, outside the uterine cavity, most commonly in the ovaries and peritoneum in the peritoneal cavity [1]. Although endometriosis is not a newly discovered disease, it still remains enigmatic. Understanding the pathophysiology of this disease is one of the challenges of gynecology and reproductive medicine. The exact mechanism of survival and proliferation of ectopic endometrial foci is unknown; however, numerous hypotheses and theories are trying to explain the pathogenesis of endometriosis [2]. These include the implantation, metastatic, or induction theories, the lympho-vascular 
embolii or genetic hypothesis, and most recently, the stem cell theory [3-7]. In recent years, many researchers have confirmed that one of the main conditions for the maintenance and development of the endometriotic implants is the presence of disorders in the immune system $[8,9]$. Ectopic endometrial lesion development is associated with complex interactions between endometrial tissue, the peritoneum, and immune cells [10]. These processes depend not only on the specific tissue characters and its ability to auto-transplant at an ectopic localization, but also on the features of the innate and adaptive immune responses [11]. All together, the persistence of ectopic endometriotic tissue is associated with uncontrolled growth, invasion of adjacent tissues, defective apoptosis, neoangiogenesis, and sustained local inflammatory responses [11,12]. Over time, this immune dysregulation can progress into a chronic state of inflammation, creating an environment conducive to increased adhesion and angiogenesis, which may drive the vicious cycle of endometriosis onset and progression [13]. As a consequence, immune system modulation and the inflammatory response promote not only the initial ectopic endometrium implantation, but also the subsequent implant maintenance and progression [13,14]. For these reasons, endometriosis is considered a chronic inflammatory disorder. All changes in the activation of immune cells and altered secretion of cytokines and growth factors lead to the creation of an inflammatory microenvironment.

Peritoneal fluid, through a direct contact with the endometrial foci of ectopic tissue, links the reproductive and the immune systems. It mostly comprises mononuclear cells, mainly macrophages, but also T and B lymphocytes and Natural Killer (NK) cells. These cells come from the blood and from the endometrium, where they are called endometriosisassociated immune cell infiltrates $[15,16]$. The constant recruiting of immune cells into the peritoneal cavity of women with endometriosis is ensured by chemokines.

Chemokines are small proteins secreted by cells which influence the immune system, with a crucial role in inflammation and immunity [17]. Representing the largest class of cytokines, chemokines play a crucial role in both physiological and pathological activities by stimulating the migration of immune cells, especially macrophages and granulocytes, through concentration gradients [18]. The main sources of chemokines are activated monocytes, macrophages, and granulocytes; however, they can also be produced by many other cells of the immune system. Chemokines are proteins with a low molecular weight of 8-12 kDa, composed of 70-130 amino acids. About 50 chemokines are currently known, but the number continues to grow [19]. Chemokines are further subdivided into four main classes: the CC chemokines, the CXC chemokines, $\mathrm{C}$ chemokines, and CX3C chemokines. This classification is based on the location of the first two cysteine (C) residues and disulphide bonds in their protein sequence [20]. In order to exert a biological effect, chemokines will bind to receptors of the G protein-coupled receptor (GPCR) superfamily, which possess seven conserved transmembrane domains with which chemokines can interact [21]. The primary function of chemokines is chemotaxis, i.e., directing the migration of leukocytes to the site of an ongoing inflammatory process [17]. Moreover, they regulate leukocyte maturation and participation in the inflammatory response, metastasis, and autoimmune diseases. Additionally, they influence the activation of adhesion molecules and cell death. They also participate in angiogenesis, embryogenesis, organogenesis and are involved in wound healing, allergies, and viral and bacterial infections [22]. Despite many years of research on the participation of chemokines in the pathogenesis of endometriosis, the obtained results do not allow for an unequivocal explanation of the function of these factors in the development of the disease. The observations indicate that the formation and development of endometriosis could be mediated by monocyte chemoattractant protein (MCP)-1 and MCP-3. However, other chemokines may be involved in this process and form together a chemokine network involved in the maintenance of inflammation within the peritoneal cavity. For this reason, we decided to evaluate the concentration of selected chemokines, such as MCP-1, MCP-2, MCP-3, MCP-4, macrophage inflammatory protein (MIP)-1 $\alpha$, MIP-1 $\beta$, eotaxin-2, eotaxin-3, epithelial-derived neutrophil activating factor (ENA)-78, and fractalkine in the peritoneal fluid of women with endometriosis. 


\section{Materials and Methods}

The study included 78 women admitted to the Clinic of Gynecology and Obstetrics of the Medical University of Silesia in Katowice for diagnostic or therapeutic laparoscopy for unexplained infertility. All women in the study had a normal menstrual cycle ( $28 \pm 4$ days) and no other pelvic disorders, chronic, autoimmune, or neoplastic diseases. Additionally, none of them had been taking any anti-inflammatory or immunomodulatory medication in the preceding 3 months. The laparoscopy was performed during the early proliferative phase of the menstrual cycle, directly after menstruation.

Endometriosis was confirmed histologically in 58 women, aged 23 to 43 years (mean age \pm SD: $33.7 \pm 6.3$ ), whose disease was scored according to the American Fertility Society (rAFS) classification [23]. Among them, 20 women were on stage I, 15 on stage II, 15 on stage III, and 8 on stage IV. Women with stage I and II endometriosis were classified as with minimal/mild endometriosis, and women stage III and IV endometriosis were classified as with moderate/severe endometriosis. In 20 women, 21 to 37 years old (mean age: $30.2 \pm 5.4$ years), used as reference group, laparoscopic examination demonstrated a normal status of the pelvic organs without any evidence of endometriosis or inflammation in the peritoneal cavity. The Ethics Committee of the Medical University of Silesia approved this study according to the criteria of the Declaration of Helsinki.

Peritoneal fluid samples were collected under direct vision from the pelvis before any operative manipulation to minimize blood contamination. Patients with bloodcontaminated material were excluded from the study. The peritoneal fluid was centrifuged immediately at $400 \times g$ for $10 \mathrm{~min}$, and supernatants were stored in aliquots at $-80^{\circ} \mathrm{C}$, until assayed. Based on a literature review, we selected a panel of 10 chemokines and customized a Multiplex Immunoassay commercial kit in the Luminex platform (Milliplex ${ }^{\circledR}$ Map Human Cytokine/Chemokine Magnetic Bead Panel I and II, Merck KGaA Darmstadt, Germany) following the manufacturer's instructions. A Luminex MAGPIX ${ }^{\circledR}$ reader was used to retrieve the results.

All results are presented as mean \pm standard deviation or median and interquartile range and were examined for normality of distribution by the Shapiro-Wilk test. Parametric data were analyzed using Student's $t$-test. For nonparametric data, Fisher's exact test (analysis of variance) was applied to indicate statistical significance because it analyzes the variance relationship both within and among groups. Correlations were tested by Spearman's rank correlation test and are presented as correlation coefficient (r). A $p<0.05$ was considered statistically significant.

\section{Results}

The study analyzed the concentrations of the following chemokines: MCP-1, MCP-2, MCP-3, MCP-4, MIP-1 $\alpha$, MIP-1 $\beta$, eotaxin-2, eotaxin-3, ENA-78, and fractalkine in the peritoneal fluid of women with endometriosis and women from the reference group. The results are presented in Table 1 and Figure 1.

\section{1. $M C P-1, M C P-2, M C P-3$, and $M C P-4$}

The analysis showed a statistically significant decreased concentration of MCP-1, MCP-2, MCP-3, and MCP-4 in the peritoneal fluid of women with endometriosis compared to that of the reference group $(p<0.001)$. The levels of the chemokines in the peritoneal fluid were assessed depending on the severity of endometriosis. The highest concentration of MCP-1 was observed in women with minimal endometriosis compared to those with mild $(p<0.001)$, moderate. and advanced disease, whereas the highest MCP-2 concentration was found in the PF of women with III stage disease. Statistically important differences were found in MCP-2 levels between women with stage I and II endometriosis $(p<0.0001)$, as well as between women with stage II and III endometriosis $(p<0.01)$ and between those with stage III and IV endometriosis $(p<0.0001)$. The highest MCP-3 level was observed in the PF of women with minimal endometriosis, but there was no statistical differences 
depending on the endometriosis stage. For MCP-4, a statistical significant difference was found only between women with stages III and IV of the disease $(p<0.01)$.

Table 1. Peritoneal level of the studied chemokines in women with endometriosis and women from the reference group.

\begin{tabular}{|c|c|c|c|c|c|}
\hline \multirow{2}{*}{ Cytokines } & \multicolumn{4}{|c|}{ Patients } & \multirow{2}{*}{$p$ Value } \\
\hline & \multicolumn{2}{|c|}{ Endometriosis $(n=58)$} & \multicolumn{2}{|c|}{ Control $(n=20)$} & \\
\hline CC $(\beta)$ chemokines & & & & & \\
\hline $\begin{array}{l}\text { МCP-1 } \\
\text { MCP-2 }\end{array}$ & $\begin{array}{r}46.90 \\
45628\end{array}$ & $(38.96-66.21)$ & 161.77 & (143.49-243.96) & $<0.001$ \\
\hline & 34.96 & $(2717-5414)$ & 1058.70 & (995.08-1146.50) & 0.0001 \\
\hline $\begin{array}{l}\text { MCP-3 } \\
\text { MCP-4 }\end{array}$ & 20 & 174 - & $\begin{array}{l}182.22 \\
37.01\end{array}$ & $(15 \% .13-242.19)$ & $<0.001$ \\
\hline $\begin{array}{l}\text { МСР-4 } \\
\text { MIP-1 }\end{array}$ & & (1) & 37. & $(36$ & .0001 \\
\hline MIP-1 & 32 & $-48.53)$ & 189.62 & (151.17-241.96) & $<0.0001$ \\
\hline MIP-1 $\beta$ & & $(22.0$ & 22.63 & $(18.02-24.19)$ & NS \\
\hline Eotaxin 2 & 902.60 & $(445.60-1036.42)$ & 252.31 & (179.51-298.82) & $<0.0001$ \\
\hline Eotaxin 3 & 28.45 & $(22.12-35.95)$ & 16.68 & $(16.13-18.00)$ & $<0.001$ \\
\hline CXC $(\alpha)$ chemokines & & & & & \\
\hline ENA-78 & 41.75 & (29.91-46.02) & 20.35 & $(18.31-22.69)$ & $<0.001$ \\
\hline $\begin{array}{c}\text { CX3C (d) chemoki } \\
\text { Fractalkine }\end{array}$ & 5823.75 & $(6025.47-11112.94)$ & 19826.46 & (15222.78-27813.28) & $<0.0001$ \\
\hline
\end{tabular}

Data are presented as median concentrations and interquartile range.

a)
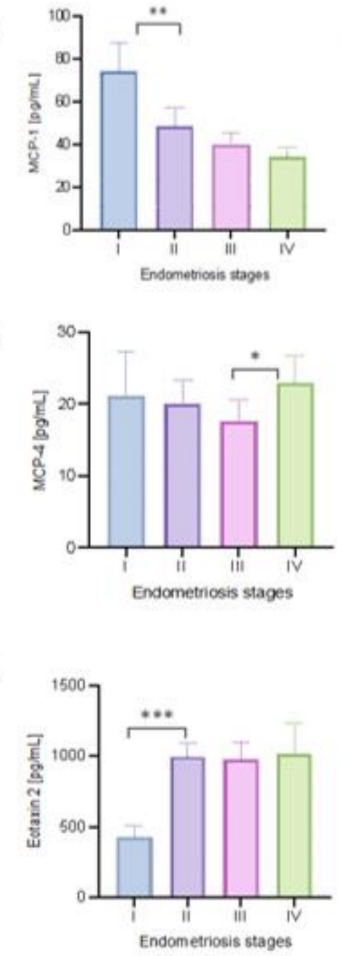

b)
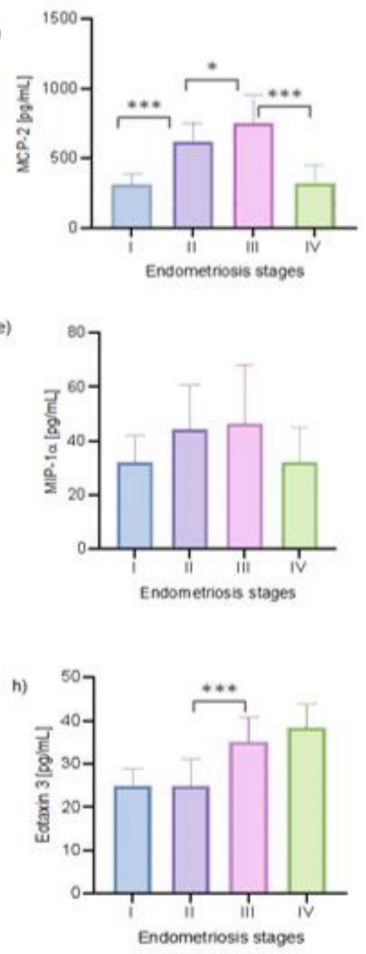
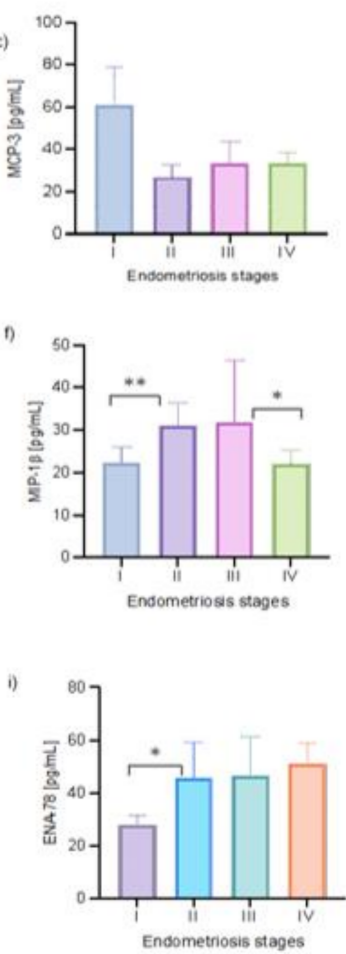

i)

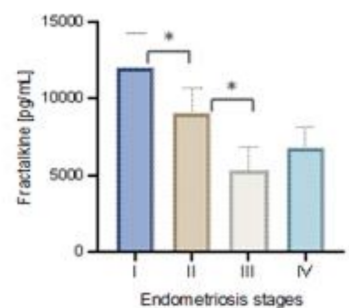

Figure 1. The concentration of the studied chemokines $(\mathbf{a}-\mathbf{j})$ in the peritoneal fluid of women with endometriosis at progressive stages. 
Due to the fact that both MCP-1 and MCP-2 exert their biological effect via the same receptors, a correlation test was performed to determine the relationship between the concentration of these two chemokines in the peritoneal fluid of women with endometriosis. The analysis showed a negative statistically significant correlation between the concentration of MCP-1 and MCP-2 $(\mathrm{r}=-0.454 ; p<0.0001)$. Additionally, there were positive, statistically significant correlations between MCP-1 and MCP-3 $(r=0.841 ; p<0.0001)$ and between MCP-1 and MCP-4 ( $\mathrm{r}=0.706 ; p<0.0001)$.

\subsection{MIP-1 $\alpha$ and MIP-1 $\beta$}

There was a statistically significant reduction of the peritoneal level of MIP- $1 \alpha$ in the endometriosis group compared to the reference group $(p<0.0001)$. No statistically significant differences depending on the stage of endometriosis were observed. The analysis of the results showed no statistically significant difference in the concentration of MIP- $1 \beta$ between the group of women with endometriosis and the reference group. There were significant differences in the level of MIP-1 $\beta$ between women with stage I and II endometriosis $(p<0.001)$ and between those with stage III and IV $(p<0.01)$ endometriosis.

\subsection{Eotaxin 2 and Eotaxin 3}

A statistically significant increase in the peritoneal levels of eotaxin 2 and eotaxin 3 in women with endometriosis compared to the reference group $(p<0.0001$ and $p<0.001$, respectively) was observed. The lowest level of eotaxin 2 was found in the peritoneal fluid of women with minimal disease, which statistically was significantly different from that in women with mild disease $(p<0.0001)$. For eotaxin 3 , a statistically significant increase in the concentration was found when comparing women with mild and severe endometriosis $(p<0.0001)$.

\subsection{ENA-78}

The analysis showed a statistically significant higher level of ENA-78 in women with endometriosis compared to the reference group $(p<0.001)$. The lowest level of ENA-78 was observed in the peritoneal fluid of women with stage I endometriosis compared to those with II stage endometriosis $(p<0.01)$.

\subsection{Fractalkine}

A lower concentration of fractalkine was observed in the group of women with endometriosis compared to the reference group $(p<0.0001)$. The highest level of fractalkine was observed in the peritoneal fluid of women with stage I endometriosis, and the concentration increase was statistically significant with respect to the levels in women with stage II endometriosis $(p<0.01)$. In turn, the fractalkine level in women with stage II endometriosis was higher compared to that in women with stage III endometriosis $(p<0.01)$.

\section{Discussion}

Disorders of the immune system and chronic inflammation play an important role in the pathogenesis of endometriosis [24]. This is indicated by an increased number of hyperactive macrophages in the peritoneal fluid of affected women, as well as altered number and activity of T lymphocytes, including Tc, Th, Treg, NK cells, and granulocytes [25,26].

The underlying reasons for the development of a chronic inflammation in women with endometriosis are not completely clear. Retrograde menstrual blood flow, as the most accepted origin of this disease, seems to have a prominent role. The presence of endometrial cells in an ectopic location causes a natural response of innate and adaptive immune system components, which try to eliminate menstrual debris and initiate tissue repair. However, the inability to deal with the persistent presence of menstrual debris over time may lead to immune system overload and subsequent immune alterations [27]. This can aggravate the inflammatory process and transform it into a chronic state. 
The constant influx of immune system cells into the peritoneal cavity is regulated by chemokines. Their primary function is chemotaxis, i.e., directing the migration of leukocytes to the site of an ongoing inflammatory process, but they also stimulate their activity [21]. The role of chemokines in the pathogenesis of endometriosis has been the subject of numerous studies for many years, and it has been confirmed that chemokines are involved in the development of endometriosis [28,29]. In addition, it is believed that chemokines may be influence the incidence of endometriosis in women in the menopausal and postmenopausal periods [30,31]. Therefore, in our work, we decided to investigate the concentration of selected chemokines in the peritoneal fluid of patients with endometriosis. We found lower peritoneal levels of MCP-1, MCP-2, MCP3, MCP-4, MIP-1 $\alpha$, and fractalkine and higher level of eotaxin-2, eotaxin-3, and ENA-78 in women with endometriosis compared to reference group. The degree of the changes in the concentration of the studied chemokines was different depending on the progressive stages of endometriosis. Most concentration changes were severe in women at late stages of the disease.

The role of MCPs in the pathogenesis of endometriosis is still poorly understood, and the results concerning their concentration, especially for MCP-1, in the peritoneal fluid and serum of women with endometriosis, are divergent. Some researchers observed an increase in the concentration of this chemokine compared to that in a reference group, which in their opinion indicates MCP-1 participation in the development of inflammation in the peritoneal cavity [32-35]. On the other hand, Margari et al. [36], similarly to our research, observed a lower concentration of MCP-1 in the PF of women with endometriosis. In their opinion, lowering the concentration of MCP-1 in patients reduces the chemotactic activity of the peritoneal fluid. This, combined with the hypothesis that the function of peritoneal macrophages in women with endometriosis is impaired, may explain the easier implantation of endometrial cells in the peritoneal cavity. However, Kim et al. [37] and Laudański et al. [38] did not show any statistically significant differences between the concentration of MCP-1 in the peritoneal fluid and in the serum of women with and without endometriosis.

The discrepancy observed by various researchers regarding the MCP-1 level in the peritoneal fluid of women with endometriosis compared to that in a reference group could be caused by many different factors. Among other things, it may be related to a different activity of the disease, the type and origin of endometrial changes, or other poorly understood factors. It should be emphasized that the measurement of the concentration of chemokines is difficult due to the short half-life of these molecules. Additionally, the differences in the results may also be related to the testing techniques, their sensitivity and the detection method used [39]. A very important factor that can influence the results is related to the hormonal changes that occur during the menstrual cycle. In our research, patients' peritoneal fluid was collected immediately after the end of menstruation, at the beginning of the follicular phase, in order to avoid the endogenous influence of sex hormones. During this period, healthy women may develop weak local menstrual inflammation, which then disappears [40].

On the other hand, in women with endometriosis, local inflammation is present all the time, and the cyclically exfoliating mucosa of the endometrium may intensify this process. Perhaps, during this period, there is an increased binding of chemokines to their receptors on target cells, which is related to the lower availability of free factors in the peritoneal fluid. However, this thesis requires confirmation and additional research. The different results regarding MCP-1 show the importance of the phase of the menstrual cycle in which the peritoneal fluid is collected for later verification and of the ability to compare test results from multiple centers. Although in 2014 an international team of experts developed guidelines for the collection of biological material for the study of endometriosis [41], comparisons are difficult to carry out due to the different procedures and health care systems in different countries. We could also consider as a limitation the detection sensitivity of multiplex immunoassays. It has been shown that, although 
multiplex immunoassays have a sensitivity comparable to that of a conventional ELISA, it is possible that they may differ in matrix beads multiplexing [42].

MCP-1, along with IL-8, is considered one of the most important cytokines involved in the pathogenesis of endometriosis. It can influence the migration of monocytes from the peritoneal blood to the peritoneal cavity, where these cells transform into macrophages and contribute to the local inflammatory process that is observed in endometriosis [34,43]. Additionally, MCP-1, may be responsible for other processes in the peritoneal cavity of affected women [44]. According to Younis et al. [32], MCP-1 stimulates the adherence of endometrial cells to the extracellular matrix and is involved in angiogenesis. It also plays an important role in the growth of ectopic endometrial tissue by stimulating macrophages, as well as by directly stimulating the proliferation of endometrial cells. Moreover, MCP-1 activates monocytes, macrophages, T lymphocytes, NK cells, basophils, and mast cells [33,36]. This suggests that all changes in the cytokine profile, especially the participation of cytokines with a pro-inflammatory profile such as IL-8, MCP-1, and IFN- $\gamma$, indicate impaired immune activity in endometriosis, which may be responsible for the occurrence and development of the disease $[33,36]$. On the other hand, factors that may play a role in the treatment of endometriosis were studied by Cakmak et al. [45]. According to their results, substances that reduce the inflammatory process in the peritoneum may slow down the formation and development of endometriosis by inhibiting the production and secretion of MCP-1.

MCP-3 has many features similar to those of MCP-1. Both stimulate Th2 lymphocyte polarization, and their concentration is elevated in many chronic inflammatory diseases. Margari et al. [36] showed there were no statistically significant differences in the peritoneal level of MCP-3 between women with endometriosis and women in a reference group. Other results were obtained by Rakhila et al. [46] who studied the influence of various chemokines, including MCP-3, on the development of endometriosis. Increased concentration of this molecule was observed in the peritoneal fluid compared to a reference group. Additionally, a higher concentration of MCP-3 was observed in patients with endometriosis at advanced stages than in those at early stages of the disease. A higher level of MCP-3 was observed in the proliferative phase of the menstrual cycle. Changes in the concentration of this and other tested chemokines in the peritoneal fluid of women with endometriosis suggest that they may contribute to the development of angiogenesis and cell proliferation [46].

MCP-2 and MCP-4 are other chemokines investigated in this study. In the available literature, there is little information on their role in the formation and development of endometriosis. However, MCP-2 is involved in activating the effector mechanisms of antiinfective immunity, for example, by activating monocytes. Chmaj-Wierzchowska et al. [47] assessed the relationship of this chemokine with the occurrence of pain in the pelvic area in women with endometrial cysts. The obtained results confirmed the participation of this molecule in the occurrence of pain in the group of examined women. So far, the role of MCP-2 in diseases other than endometriosis has been assessed. MCP-2 was found in the amniotic fluid of women with preterm labor before 34 weeks of gestation, infection, and inflammation in the amniotic cavity [48]. In addition, MCP-4 acts as an effective chemoattractant for monocytes and T lymphocytes and is capable of interacting with three different receptors: CCR3, CCR24, and CCR55. On the other hand, it was investigated how MCP-4 influences the movement and migration of lymphocytes during their maturation and differentiation in peripheral lymphoid organs [49].

In addition to proteins from the MCP group, chemokines from the CC subfamily were also studied $[36,50,51]$. The results indicate that these chemokines may be associated with the pathogenesis of the disease. Both MIP- $1 \alpha$ and MIP- $1 \beta$ were originally identified as soluble factors secreted by activated macrophages [52]. Similar to the results regarding MCP, those on the concentration of MIP in the peritoneal fluid in women with endometriosis from multiple centers are inconsistent. Mao et al. [53] observed a decreased concentration of MIP- $1 \alpha$ in the fluid collected from oocytes of women with endometriosis compared to those from a reference group. On the other hand, Malutan et al. [34] noted a very low detection rate of MIP- $1 \alpha$ and MIP-1 $\beta$. Many studies assessed MIP-3 concentration 
in both the peritoneal fluid and the serum of women with endometriosis [38]. These studies showed that the detection of increased concentrations of MIP-3 $\beta$ as well as of MCP-1 and IL- 8 in the peritoneal fluid of these women may be helpful in the diagnosis of endometriosis [54]. Many authors pointed out that the determination of the concentration of this chemokine panel in the peripheral blood of women with endometriosis may allow an early non-invasive diagnosis, facilitating the diagnosis of this disease [28]. However, this thesis requires confirmation.

Eosinophils and basophils are also involved in the pathogenesis of endometriosis, especially in the early stages of its development [55-58]. These cells play a role in the immune response that is specifically directed against ectopic endometrial cells. In addition, eosinophils are involved in a more general type of inflammatory response associated with wound healing and tissue remodeling, induced by endometrial changes. There is increasing evidence that eosinophils regulate the multiplication and activity of fibroblasts and stimulate collagen synthesis, which may be of great importance in the formation of adhesions and scarring within the peritoneal cavity in women with endometriosis [56]. For this reason, we evaluated the concentrations of eotaxin- 2 and eotaxin-3 in endometriosis patients. However, there is only limited information of the role of these chemokines in the formation and development of endometriosis in the literature. Meanwhile, the results of our research showed an increase in their concentration in the peritoneal fluid of affected women, which may indicate their participation in the pathogenesis of this disease. The studies conducted so far have allowed to assess the occurrence of the family of this chemokines as a whole, without distinguishing between its individual members. Hornung et al. [59] confirmed the presence of eotaxin in the tissue of the ectopic endometrium, and its distribution was similar to that observed in the eutopic endometrium. Additionally, the concentration of eotaxin in the peritoneal fluid was significantly higher in women with moderate or severe endometriosis than in women with minimal or mild endometriosis and in women in the control group. In addition, in vitro studies have shown that ectopic endometrial cells stimulated with estradiol, medroxyprogesterone acetate, TNF- $\alpha$, IFN- $\gamma$, and IL-4 secrete eotaxin. Its secretion was increased in women with endometriosis and depended on the phase of the menstrual cycle $[59,60]$. Similar to the results of our work, Bersinger et al. [61] showed the increased concentration of eotaxin in the peritoneal fluid of endometriosis patients, which was associated with its increased production by endometrial cells. Santonastaso et al. [62] showed that the concentration of eotaxin-1 (CCL11) was significantly increased in the follicular fluid of women with endometriosis compared to a control group, which may affect the development of infertility accompanying endometriosis. On the other hand, Rocha et al. [63] and Măluțan [34] showed a decreased concentration of eotaxin- 1 in the serum and plasma of women with endometriosis. According to these researchers, this chemokine cannot be used as a marker for the diagnosis of this disease.

Another molecules of the group of CXC $(\alpha)$ chemokines that was assessed is ENA-78. There are few studies in the available literature on the occurrence of this chemokine in women with endometriosis. Bersinger et al. [61] observed that in women with endometriosis, the concentration of ENA-78 in the peritoneal fluid was increased compared to the concentration in healthy women. In turn, Nishida et al. [64] showed that endometrial cells produce and secrete various chemokines, including ENA-78, IL-8, MCP-1, MIP- $1 \alpha$, and eotaxins. Since ENA-78 plays an important role in the neovascularization surrounding endometriotic lesions by increasing other angiogenic factors, its increased secretion might participate in the pathogenesis of endometriosis [64]. The last chemokine of the CX3C subfamily whose concentration was tested is fractalkine. It is known that this chemokine has not only important functions in the immune system but also participates in the wound healing process, among other processes. It is known from the literature that fractalkine has a chemotactic effect on monocytes and mast cells and also mediates the adhesion and migration of lymphocytes [65]. Pain is the most serious and common symptom of endometriosis. Its basic pathogenetic mechanism is poorly understood. Fractalkine is known to play an important role in various forms of neuropathic pain, while its role in 
endometriotic pain is unknown [66]. Hou et al. [67] found that eutopic endometrium from patients with endometriosis had a significantly higher expression of fractalkine compared to normal endometrium, and ectopic tissues showed the highest expression. Additionally, the concentration of fractalkine in the peritoneal fluid of patients with endometriosis was higher than in the control group and positively correlated with the severity of the disease (67). Other results were obtained by Shimoya et al. [68] who assessed the relationship between the concentration of fractalkine in the peritoneal fluid and the occurrence of endometriosis. They suggested that the reduced concentration of this chemokine in women with endometriosis compared to a reference group may be associated with the development of endometriosis, which was also confirmed by the results obtained in this study. In addition, Western blot and immunohistochemical analyses using anti-fractalkine antibodies as well as molecular studies have shown that peritoneal fluid cells as well as the peritoneal membrane itself may be important sources of fractalkine in the peritoneal fluid. Fractalkine protects the peritoneal cavity against infection and is involved in the maintenance of homeostasis of the immune system in the peritoneal cavity in case of peritonitis and during the elimination of pathogens. On the other hand, a reduced concentration of this chemokine in the peritoneal fluid may contribute to the development of chronic inflammation and disease [68].

In conclusion, changes in the concentration of all studied chemokines in the peritoneal fluid of women with endometriosis indicate the participation of these molecules in the pathogenesis of the disease. Changes in the secretion of chemokines in the peritoneal fluid of women with endometriosis can lead to an abnormal immune response to ectopic endometrial cells, which facilitates their movement to unusual places in the body and the formation of foci. Explaining these mechanisms is important for a better understanding of the pathogenesis of this disease and may be helpful in the search for new diagnostic and therapeutic options for endometriosis. The different involvement of the studied chemokines in subsequent stages of the disease, indicates their variable distribution and the participation of various immune cells in an ongoing inflammatory process. This indicates a significant role of an impaired immune response in the development of this disease and the presence of local inflammation in the peritoneal cavity of women with endometriosis.

Author Contributions: Conceptualization, M.S.-K., Z.K.-A., J.S. and A.M.-P.; Methodology, M.S.-K., D.W., P.K.-D., A.E., A.J. and J.J.; Supervision, A.M.-P.; Visualization, J.S.; Writing-original draft, M.S.-K., Z.K.-A. and J.S.; Writing-review \& editing, Z.K.-A. and A.M.-P. All authors have read and agreed to the published version of the manuscript.

Funding: This research received no external funding.

Conflicts of Interest: The authors declare no conflict of interest.

\section{References}

1. Zondervan, K.T.; Becker, C.M.; Koga, K.; Missmer, S.A.; Taylor, R.N.; Viganò, P. Endometriosis. Nat. Rev. Dis. Primers 2018, 4, 9. [CrossRef] [PubMed]

2. Gruber, T.M.; Mechsner, S. Pathogenesis of endometriosis: The origin of pain and subfertility. Cells 2021, 10, 1381. [CrossRef]

3. Koninckx, P.R.; Ussia, A.; Adamyan, L.; Wattiez, A.; Gomel, V.; Martin, D.C. Pathogenesis of endometriosis: The genetic/epigenetic theory. Fertil. Steril. 2019, 111, 327-340. [CrossRef]

4. Czyzyk, A.; Podfigurna, A.; Szeliga, A.; Meczekalski, B. Update on endometriosis pathogenesis. Minerva Ginecol. 2017, 69, 447-461. [CrossRef] [PubMed]

5. Ulukus, M. Stem cells in endometrium and endometriosis. Womens Health 2015, 11, 587-595. [CrossRef] [PubMed]

6. Lalami, I.; Abo, C.; Borghese, B.; Chapron, C.; Vaiman, D. Genomics of endometriosis: From genome wide association studies to exome sequencing. Int. J. Mol. Sci. 2021, 22, 7297. [CrossRef] [PubMed]

7. Borghese, B.; Zondervan, K.T.; Abrao, M.S.; Chapron, C.; Vaiman, D. Recent insights on the genetics and epigenetics of endometriosis. Clin. Genet. 2017, 91, 254-264. [CrossRef] [PubMed]

8. Zhang, T.; De Carolis, C.; Man, G.C.W.; Chi Chiu Wang, C.C. The link between immunity, autoimmunity and endometriosis: A literature update. Autoimmun. Rev. 2018, 17, 945-955. [CrossRef]

9. Vallvé-Juanico, J.; Houshdaran, S.; Giudice, L.C. The endometrial immune environment of women with endometriosis. Hum. Reprod. Update 2019, 25, 564-591. [CrossRef] 
10. Parkin, K.L.; Fazleabas, A.T. Uterine leukocyte function and dysfunction: A hypothesis on the impact of endometriosis. Am. J. Reprod. Immunol. 2016, 75, 411-417. [CrossRef]

11. Novembri, R.; Carrarelli, P.; Toti, P.; Rocha, A.L.; Borges, L.E.; Reis, F.M.; Piomboni, P.; Florio, P.; Petraglia, F. Urocortin 2 and urocortin 3 in endometriosis: Evidence for a possible role in inflammatory response. Mol. Hum. Reprod. 2011, 17, 587-593. [CrossRef] [PubMed]

12. Symons, L.K.; Miller, J.E.; Kay, V.R.; Marks, R.M.; Liblik, K.; Koti, M.; Tayade, C. The immunopathophysiology of endometriosis. Trends Mol. Med. 2018, 24, 748-762. [CrossRef] [PubMed]

13. Taylor, H.S.; Kotlyar, A.M.; Flores, V.A. Endometriosis is a chronic systemic disease: Clinical challenges and novel innovations. Lancet 2021, 397, 839-852. [CrossRef]

14. Cacciottola, L.; Donnez, J.; Dolmans, M.M. Can endometriosis-related oxidative stress pave the way for new treatment targets? Int. J. Mol. Sci. 2021, 22, 7138. [CrossRef] [PubMed]

15. Hutter, S.; Heublein, S.; Knabl, J.; Andergassen, U.; Vrekoussis, T.; Makrigiannakis, A.; Friese, K.; Mayr, D.; Jeschke, U. Macrophages: Are they involved in endometriosis, abortion and preeclampsia and how? J. Nippon. Med. Sch. 2013, 80, 97-103. [CrossRef] [PubMed]

16. Scheerer, C.; Bauer, P.; Chiantera, V.; Sehouli, J.; Kaufmann, A.; Mechsner, S. Characterization of endometriosis associated immune cell infiltrates (EMaICI). Arch. Gynecol. Obstet. 2016, 294, 657-664. [CrossRef] [PubMed]

17. Griffith, J.W.; Sokol, C.L.; Luster, A.D. Chemokines and chemokine receptors, positioning cells for host defense and immunity. Annu. Rev. Immunol. 2014, 32, 659-702. [CrossRef]

18. Ruytinx, P.; Proost, P.; Van Damme, J.; Struyf, S. Chemokine-induced macrophage polarization in inflammatory conditions. Front. Immunol. 2018, 9, 1930. [CrossRef]

19. Poeta, V.M.; Massara, M.; Capucetti, A.; Bonecchi, R. Chemokines and chemokine receptors: New targets for cancer immunotherapy. Front. Immunol. 2019, 10, 379. [CrossRef]

20. Hughes, C.E.; Nibbs, R.J.B. A guide to chemokines and their receptors. FEBS J. 2018, 285, 2944-2971. [CrossRef]

21. Bennett, L.D.; Fox, J.M.; Signoret, N. Mechanisms regulating chemokine receptor activity. Immunology 2011, 134, 246-256. [CrossRef]

22. Stone, M.J.; Hayward, J.A.; Huang, C.; Huma, Z.E.; Sanchez, J. Mechanisms of regulation of the chemokine-receptor network. Int. J. Mol. Sci. 2017, 18, 342. [CrossRef]

23. American Society for Reproductive Medicine. Revised American Society for Reproductive Medicine classification of endometriosis: 1996. Fertil. Steril. 1997, 67, 817-821. [CrossRef]

24. Greene, A.D.; Lang, S.A.; Kendziorski, J.A.; Sroga-Rios, J.M.; Herzog, T.J.; Burns, K.A. Endometriosis: Where are we and where are we going? Reproduction 2016, 152, 63-78. [CrossRef] [PubMed]

25. Izumi, G.; Koga, K.; Takamura, M.; Makabe, T.; Satake, E.; Takeuchi, A.; Taguchi, A.; Urata, Y.; Fujii, T.; Osuga, Y. Involvement of immune cells in the pathogenesis of endometriosis. J. Obstet. Gynaecol. Res. 2018, 44, 191-198. [CrossRef] [PubMed]

26. Tanaka, Y.; Mori, T.; Ito, F.; Koshiba, A.; Takaoka, O.; Kataoka, H.; Maeda, E.; Okimura, H.; Mori, T.; Kitawaki, J. Exacerbation of endometriosis due to regulatory T-cell dysfunction. J. Clin. Endocrinol. Metab. 2017, 102, 3206-3217. [CrossRef] [PubMed]

27. Giacomini, E.; Minetto, S.; Piani, L.L.; Pagliardini, L.; Somigliana, E.; Viganò, P. Genetics and inflammation in endometriosis: Improving knowledge for development of new pharmacological strategies. Int. J. Mol. Sci. 2021, 22, 9033. [CrossRef]

28. Borrelli, G.M.; Carvalho, K.I.; Kallas, E.G.; Mechsner, S.; Baracat, E.C.; Abrão, M.S. Chemokines in the pathogenesis of endometriosis and infertility. J. Reprod. Immunol. 2013, 98, 1-9. [CrossRef]

29. Coutinho, L.M.; Ferreira, M.C.; Rocha, A.L.L.; Carneiro, M.M.; Reis, F.M. New biomarkers in endometriosis. Adv. Clin. Chem. 2019, 89, 59-77.

30. Streuli, I.; Gaitzsch, H.; Wenger, J.M.; Petignat, P. Endometriosis after menopause: Physiopathology and management of an uncommon condition. Climacteric 2017, 20, 138-143. [CrossRef]

31. Szubert, M.; Suzin, J.; Wierzbowski, T.; Kowalczyk-Amico, K. CA-125 concentration in serum and peritoneal fluid in patients with endometriosis-preliminary results. Arch. Med. Sci. 2012, 8, 504-508. [CrossRef] [PubMed]

32. Younis, A.; Hawkins, K.; Mahini, H.; Butler, W.; Garelnabi, M. Serum tumor necrosis factor- $\alpha$, interleukin-6, monocyte chemotactic protein-1 and paraoxonase-1 profiles in women with endometriosis, pcos, or unexplained infertility. J. Assist. Reprod. Genet. 2014, 31, 1445-1451. [CrossRef]

33. Măluțan, A.M.; Drugan, T.; Ciortea, R.; Bucuri, C.; Rada, M.P.; Mihu, D. Endometriosis-associated changes in serum levels of interferons and chemokines. Turk. J. Med. Sci. 2017, 47, 115-122. [CrossRef] [PubMed]

34. Tao, Y.; Zhang, Q.; Huang, W.; Zhu, H.; Zhang, D.; Luo, W. The peritoneal leptin, MCP-1 and TNF- $\alpha$ in the pathogenesis of endometriosis-associated infertility. Am. J. Reprod. Immunol. 2011, 65, 403-406. [CrossRef] [PubMed]

35. Jørgensen, H.; Hill, A.S.; Beste, M.T.; Kumar, M.P.; Chiswick, E.; Fedorcsak, P.; Isaacson, K.B.; Lauffenburger, D.A.; Griffith, L.G.; Qvigstad, E. Peritoneal fluid cytokines related to endometriosis in patients evaluated for infertility. Fertil. Steril. 2017, 107, 1191-1199.e2. [CrossRef]

36. Margari, K.M.; Zafiropoulos, A.; Hatzidaki, E.; Giannakopoulou, C.; Arici, A.; Matalliotakis, I. Peritoneal fluid concentrations of $\beta$-chemokines in endometriosis. Eur. J. Obstet. Gynecol. Reprod. Biol. 2013, 169, 103-107. [CrossRef] [PubMed] 
37. Kim, J.Y.; Kim, H.; Suh, C.S.; Kim, S.H.; Choi, Y.M.; Kim, J.G. The G(-2518)A polymorphism of monocyte chemotactic protein-1 (MCP-1) and its serum and peritoneal fluid levels in Korean women with endometriosis. Eur. J. Obstet. Gynecol. Reprod. Biol. 2008, 139, 106-110. [CrossRef]

38. Laudański, P.; Szamatowicz, J.; Oniszczuk, M. Profiling of peritoneal fluid of women with endometriosis by chemokine protein array. Adv. Med. Sci. 2006, 51, 148-152.

39. Kalu, E.; Sumar, N.; Giannopoulos, T.; Patel, P.; Croucher, C.; Sherriff, E.; Bansal, A. Cytokine profiles in serum and peritoneal fluid from infertile women with and without endometriosis. J. Obstet. Gynaecol. Res. 2007, 33, 490-495. [CrossRef]

40. Evans, J.; Salamonsen, L.A. Inflammation, leukocytes and menstruation. Rev. Endocrinol. Metab. Disord. 2012, 13, 277-288. [CrossRef] [PubMed]

41. Fassbender, A.; Rahmioglu, N.; Vitonis, A.; Viganò, P.; Giudice, L.C.; D’Hooghe, T.M.; Hummelshoj, L.; Adamson, L.; Becker, C.M.; Missmer, S.A.; et al. World endometriosis research foundation endometriosis phenome and biobanking harmonisation project: IV. Tissue collection, processing, and storage in endometriosis research. Fertil. Steril. 2014, 102, 1244-1253. [CrossRef] [PubMed]

42. Elshal, M.F.; McCoy, J.P. Multiplex bead array assays: Performance evaluation and comparison of sensitivity to ELISA. Methods 2006, 38, 317-323. [CrossRef] [PubMed]

43. Waiyaput, W.; Pumipichet, S.; Weerakiet, S.; Rattanasiri, S.; Sophonsritsuk, A. Effect of simvastatin on monocyte chemoattractant protein-1 expression in endometriosis patients: A randomized controlled trial. BMC Womens Health 2017, 17, 89. [CrossRef] [PubMed]

44. Veillat, V.; Carli, C.; Metz, C.N.; Al-Abed, Y.; Naccache, P.H.; Akoum, A. Macrophage migration inhibitory factor elicits an angiogenic phenotype in human ectopic endometrial cells and triggers the production of major angiogenic factors via CD44, CD74, and MAPK signaling pathways. J. Clin. Endocrinol. Metab. 2010, 95, 403-412. [CrossRef]

45. Calmak, H.; Basar, M.; Seval-Celik, Y.; Osteen, K.G.; Duleba, A.J.; Taylor, H.S.; Lockwood, C.J.; Arici, A. Statins inhibit monocyte chemotactic protein 1 expression in endometriosis. Reprod. Sci. 2012, 19, 572-579. [CrossRef]

46. Rakhila, H.; Al-Akoum, M.; Bergeron, M.E.; Leboeuf, M.; Lemyre, M.; Akoum, A.; Pouliot, M. Promotion of angiogenesis and proliferation cytokines patterns in peritoneal fluid from women with endometriosis. J. Reprod. Immunol. 2016, 116, 1-6. [CrossRef]

47. Chmaj-Wierzchowska, K.; Kampioni, M.; Wilczak, M.; Sajdak, S.; Opala, T. The role of chemokine and non-chemokine factors in pain-related complaints in patients with endometrial cysts. Ginekol. Pol. 2015, 86, 94-99. [CrossRef] [PubMed]

48. Jacobsson, B.; Holst, R.M.; Andersson, B.; Hagberg, H. Monocyte chemotactic protein-2 and -3 in amniotic fluid: Relationship to microbial invasion of the amniotic cavity, intra-amniotic inflammation and preterm delivery. Acta Obstet. Gynecol. Scand. 2005, 84, 566-571. [CrossRef] [PubMed]

49. Waśniowska, K. Chemokiny-perspektywy zastosowania związków blokujących ich działanie w terapi. Postep. Hig. Med. Dosw. 2004, 58, 37-46.

50. Jabłoński, G.; Sobkiewicz, B.; Kaczmarek, M.; Krygier, A.; Bieńkiewicz, J.; Malinowski, A. Serum concentrations of CCL20/MIP3alpha in women with endometriosis. Prz. Menop. 2019, 18, 9-14. [CrossRef]

51. Na, Y.I.; Lee, D.H.; Kim, S.C.; Joo, J.K.; Wang, J.W.; Jin, J.O.; Kwak, J.Y.; Lee, K.S. Effects of peritoneal fluid from endometriosis patients on the release of monocyte-specific chemokines by leukocytes. Arch. Gynecol. Obstet. 2011, 283, 1333-1341. [CrossRef] [PubMed]

52. Hata, H. Bone lesions and macrophage inflammatory protein-1 alpha (MIP-1 $\alpha)$ in human multiple myeloma. Leuk. Lymphoma. 2005, 46, 967-972. [CrossRef]

53. Mao, X.D.; Hu, C.Y.; Zhu, M.C.; Ou, H.L.; Qian, Y.L. Immunological microenvironment alterations in follicles of women with proven severe endometriosis undergoing in vitro fertilization. Mol. Biol. Rep. 2019, 46, 4675-4684. [CrossRef] [PubMed]

54. Keyama, K.; Kato, T.; Kadota, Y.; Erdenebayar, O.; Kasai, K.; Kawakita, T.; Tani, A.; Matsui, S.; Iwasa, T.; Yoshida, K. Lipopolysaccharide promotes early endometrial-peritoneal interactions in a mouse model of endometriosis. J. Med. Investig. 2019, 66, 70-74. [CrossRef] [PubMed]

55. Augoulea, A.; Mastorakos, G.; Lambrinoudaki, I.; Christodoulakos, G.; Creatsas, G. The role of the oxidative-stress in the endometriosis-related infertility. Gynecol. Endocrinol. 2009, 25, 75-81. [CrossRef]

56. Blumenthal, R.D.; Samoszuk, M.; Taylor, A.; Brown, G.; Alisauskas, R.; Goldenberg, D.M. Degranulating eosinophils in human endometriosis. Am. J. Pathol. 2000, 156, 1581-1588. [CrossRef]

57. Eidukaite, A.; Tamosiunas, V. Activity of eosinophils and immunoglobulin E concentration in the peritoneal fluid of women with endometriosis. Clin. Chem. Lab. Med. 2004, 42, 590-594. [CrossRef]

58. Hong, J.Y. The effect of preoperative ketorolac on WBC response and pain in laparoscopic surgery for endometriosis. Yonsei Med. J. 2005, 46, 812-817. [CrossRef]

59. Hornung, D.; Sotlar, K. Localization in tissues and secretion of eotaxin by cells from normal endometrium and endometriosis 1. J. Clin. Endocrinol. Metab. 2000, 85, 2604-2608. [CrossRef]

60. Ouyang, Z.; Osuga, Y.; Hirota, Y.; Hirata, T.; Yoshino, O.; Koga, K.; Yano, T.; Taketani, Y. Interleukin-4 induces expression of eotaxin in endometriotic stromal cells. Fertil. Steril. 2010, 94, 58-62. [CrossRef]

61. Bersinger, N.A.; Dechaud, H.; McKinnon, B.; Mueller, M.D. Analysis of cytokines in the peritoneal fluid of endometriosis patients as a function of the menstrual cycle stage using the Bio-Plex ${ }^{\circledR}$ platform. Arch. Physiol. Biochem. 2012, 118, 210-218. [CrossRef] 
62. Santonastaso, M.; Pucciarelli, A.; Costantini, S.; Caprio, F.; Sorice, A.; Capone, F.; Natella, A.; Iardino, P.; Colacurci, N.; Chiosi, E. Metabolomic profiling and biochemical evaluation of the follicular fluid of endometriosis patients. Mol. Biosyst. 2017, 13, 1213-1222. [CrossRef] [PubMed]

63. Rocha, A.L.; Vieira, E.L.; Maia, L.M.; Teixeira, A.L.; Reis, F.M. Prospective evaluation of a panel of plasma cytokines and chemokines as potential markers of pelvic endometriosis in symptomatic women. Gynecol. Obstet. Investig. 2016, 81, 512-517. [CrossRef] [PubMed]

64. Nishida, M.; Nasu, K.; Narahara, H. Role of chemokines in the pathogenesis of endometriosis. Front. Biosci. 2011, 3, 1196-1204. [CrossRef] [PubMed]

65. Bobrowski, M.; Kuna, P.; Pietruczuk, M. Role of chemokines in asthma. J. Lab. Diagn. 2011, 47, 323-330.

66. Liu, Z.; Chen, S.; Qiu, C.; Sun, Y.; Li, W.; Jiang, J.; Zhang, J.M. Fractalkine/CX3CR1 Contributes to endometriosis-induced neuropathic pain and mechanical hypersensitivity in rats. Front. Cell. Neurosci. 2018, 12, 495. [CrossRef] [PubMed]

67. Hou, X.X.; Zhou, W.J.; Wang, X.Q.; Li, D.J. Fractalkine/CX3CR1 is involved in the pathogenesis of endometriosis by regulating endometrial stromal cell proliferation and invasion. Am. J. Reprod. Immunol. 2016, 76, 318-325. [CrossRef] [PubMed]

68. Shimoya, K.; Zhang, Q.; Temma-Asano, K.; Hayashi, S.; Kimura, T.; Murata, Y. Fractalkine in the peritoneal fluid of women with endometriosis. Int. J. Gynaecol. Obstet. 2005, 91, 36-41. [CrossRef] 